\title{
ASEAN Journal of Science and Engineering
}

Journal homepage: http://ejournal.upi.edu/index.php/AJSE/

\section{Building Information Modeling (BIM) as Tool to Develop Solution for Bridge Rehabilitation}

\author{
Pratiksha B. Vanjari*, Sushma S. Kulkarni \\ Department of Civil Engineering-Construction Management, Rajarambapu Institute of Technology, \\ Maharashtra, India \\ Correspondence: E-mail: vanjari.pratiksha@gmail.com
}

\begin{abstract}
A B S T RACT
Building Information Modeling (BIM) consists of processes that produce and handle information during the life cycle of a building. BIM may also be a technique involving the development and management of digital representations of a building or facility's physical and useful features. In 2D BIM software package programs, the paper explains the threedimensional (3D) modeling of the project and the multidimensional (4D) modeling using another BIM viewer. Revit model is created based on primary data that visualizes the bridge. For analysis, dead load and moving load are considered. From the result analysis of the structure, an approach is provided to repair the Bridge using BIM. As per IRC: SP -40 (Guidelines for techniques for strengthening and rehabilitation of bridges). This paper is an attempt to build a model that could demonstrate the use of BIM for bridge rehabilitation.
\end{abstract}

\begin{tabular}{l}
\multicolumn{1}{c}{ A R T I C L E I N F O } \\
Article History: \\
Submitted/Received 11 Nov 2020 \\
First revised 04 Mar 2021 \\
Accepted 12 Aug 2021 \\
First available online 17 Aug 2021 \\
Publication date 01 Mar 2022 \\
Keyword: \\
BIM, \\
Bridge, \\
Model, \\
Rehabilitation.
\end{tabular}

ARTICLE INFO

First revised 04 Mar 2021

Accepted 12 Aug 2021

Publication date 01 Mar 2022

Rehabilitation. 


\section{INTRODUCTION}

Building Information Modeling (BIM) is a powerful methodology that has been enforced with success within the domain of Architecture, Engineering, and Construction (AEC). BIM uses concepts of science and technology. It uses mathematics, algorithms, and science to visualize the structure in 3D. BIM software is used for modeling buildings. It is a holistic method of documentation useful for organizational visualization and implementation of construction such as calculation, programming, and synchronization of styles. Recognizing the issues before actual construction resolves the problems that successively save time and money. BIM technique involves the development and management of digital representations of physical and useful building characteristics or linked infrastructure. BIM tools alter the details of building along with the phases of appearance, production, maintenance, management, and demolition throughout their life cycle (McGuire, 2016).

Several studies underline that BIM's relevance to the horizontal framework is of growing interest (Clevenger, 2014; Marzouk, 2012). Some of them are: the project event and the expected simulation with an exact set of BIM resources; the advantages and satisfaction of BIM integration in bridge projects are as value control, support for decision-making, reduction of design errors, identification of interface problems, enhancement of visual perception, support for manufacturing, support for maintenance and management of infrastructure. The present research work is an effort to develop a model that highlights the first application of BIM for bridge rehabilitation.

The objective of the research work is to evaluate the current capability of BIM instruments earlier used in the bridge infrastructure market. The restoration of a bridge process was studied for this purpose. Various software is used to determine the advantages and disadvantages inherent in the system.

The evaluation and examination of the current bridge condition offered a framework in the suggestion of a different approach. The real-life problem of an existing 15-year-old bridge is under consideration. Due to high flood discharge, the deck slab shifted to the path of water flow, and the expansion joint, bearing pad, pipe railing, and approach road of the Bridge got damaged. Generally, damage to the bridge depends on the time it was underwater and the type of debris that is collected and passed under the bridge component.

BIM is a process that starts with the creation of an analytical 3D model and the management of simulation over the entire life cycle of the project (planning, design, development, operation, and maintenance). BIM combines people and technology to streamline time and cost to increase building performance. BIM is not just a software set or a 3D model, but also the large quantities of data that make up the project as well as the process of sharing that data with other stakeholders.

The detailed model contains all the necessary data and geometry for the BIM system. Revit is a software that is widely used because it includes categories of objects. Revit terminology has custom families and has a user-defined parameter. Revit is software that is used to design a structure with the structural building (Slab, Beam, Column, and Footing) to get a better visualization of 3D modeling using Revit-Rendering. It is predicated that the next version of the model will notify the decision-making and processes of facility management once the building is completed, facilitating preventive maintenance and repair.

Staad.Pro is one of the most widely used software for structural analysis. It gives various forms of analysis from the traditional static analysis of geometrically non-linear analysis or buckling analysis. 
79 | ASEAN Journal of Science and Engineering, Volume 2 Issue 1, March 2022 Hal 77-9o

After successful implementation of the 3D model, it is applied for shows detailed planning and visual construction simulation by using Neviswork.

\section{METHODS}

\subsection{Primary Data Collection}

In Sangli District, the bridge is located on the Krishna River at village Satapewadi which was constructed in 2005. The length of Satapewadi bridge is $278 \mathrm{~m}$ (L.H.S. $=118.50 \mathrm{~m}+$ Spillway= $113.50 \mathrm{~m}+$ R.H.S. $=46 \mathrm{~m}$ ). The maximum height of the bridge is $37.50 \mathrm{~m}$. The overall width of the bridge is $6.402 \mathrm{~m}$. The location of the bridge is illustrated in Google map Figure 1.

During the recent floods in August 2019, the deck slab has got disturbed because of the sudden surge of floodwater and excessive water pressure created due to vegetation and debris carries along with water. Due to flood 15 deck slabs except the first 3 on the left side and the last 1 on the right side of the bridge have moved downwards towards the stream. The Deck slab of the bridge got displaced Figure 2 a shown in table Table $\mathbf{1}$ and also wearing a coat of the joints has got damaged. The details are shown in Figure $\mathbf{2} \mathbf{b}$.

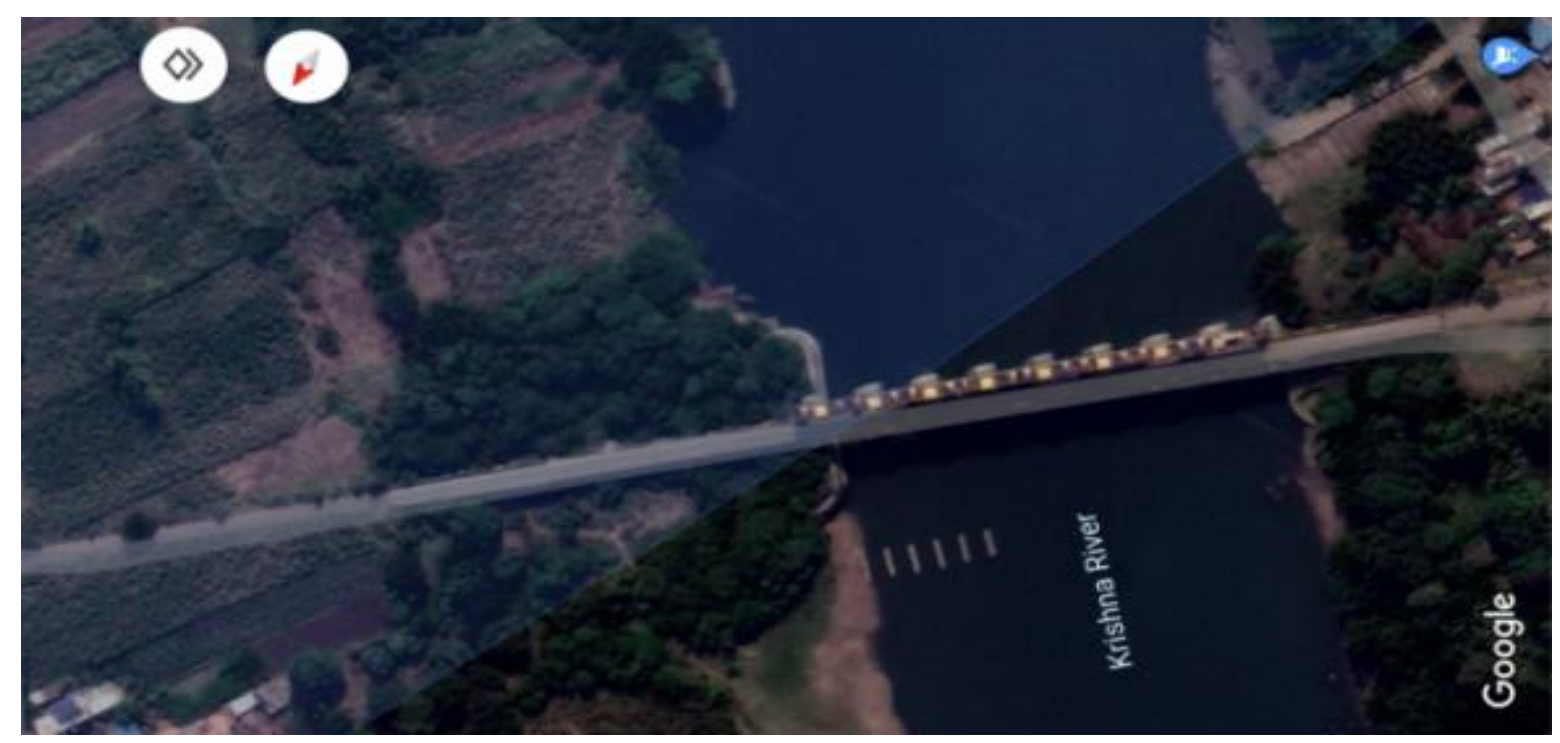

Figure 1. Google map.

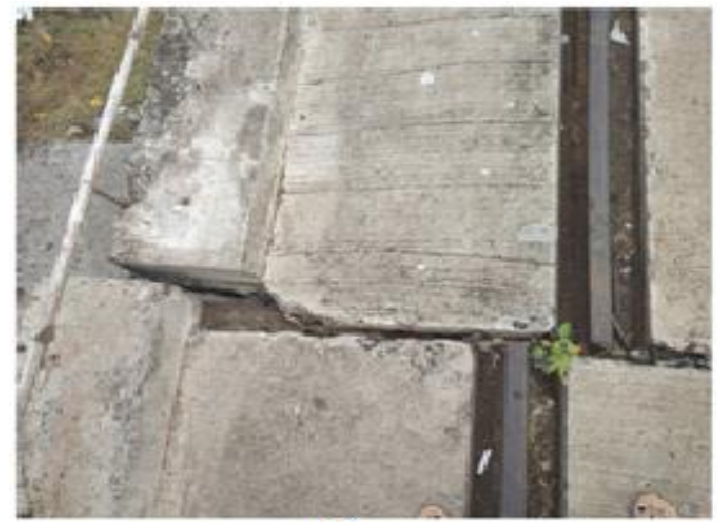

a)

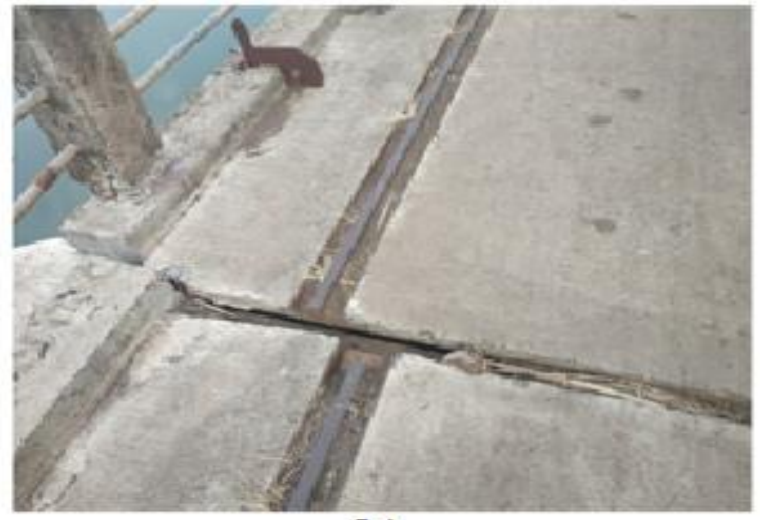

b)

Figure 2. a) Displaced deck slab; b) Damaged expansion joint. 
Table 1. Deck slab damaged.

\begin{tabular}{ccc}
\hline Deck Slab Panel number & \multicolumn{2}{c}{ Slab Slipped Distance $(\mathbf{m m})$} \\
\cline { 2 - 3 } & Left Side & Right Side \\
\hline 5 & 130 & 225 \\
6 & 225 & 225 \\
7 & 230 & 390 \\
8 & 300 & 300 \\
9 & 115 & 200 \\
\hline
\end{tabular}

It is also observed during the inspection that pipe railing and approach road on both sides of the bridge have got damaged due to flood water flow.

A visual examination of the bridge case study has been carried out and extensive data on the aspect is collected. The severity, location of the damage caused by the forms of cracking, spalling, and delamination damage to each bridge superstructure feature which is included in the items are reported during the inspection.

\subsection{Building a 3D Model}

Based on the collection of primary data the 3D model is prepared. To prepare the model of each component is marked, which are placed at substructure and superstructure. The level of each component as a foundation, pier top, lower bearing, top bearing, tee beam, and deck slab is marked. A section view of the bridge with a view from edge-on to the T-Beam or (Tee beam) is shown in Figure $3 a$.

The list of damaged elements with their Revit family, type, and bridge component Table 2 is shown as follows.

Access to a BIM model provides, benefit from its graphical and photorealistic rendering capabilities. If a bridge is to be remodeled, or a major retrofit and rehabilitation is necessary, BIM could be used as a visualization tool to present proposed renovations to the public or interested stakeholders. This is a view looking up at the bridge from the camera view. Refer to Figure $\mathbf{3 b}$ for details.

Table 2. Details of damaged elements.

\begin{tabular}{cccc}
\hline Revit Family & Revit Type & $\begin{array}{c}\text { Bridge } \\
\text { Component }\end{array}$ & $\begin{array}{c}\text { Bridge Structural } \\
\text { Usage }\end{array}$ \\
\hline Bearing & $\begin{array}{c}\text { Neoprene Bearing } \\
8^{\prime \prime *} 8^{\prime \prime}\left(0.2 \mathrm{~m}^{*} 0.2 \mathrm{~m}\right)\end{array}$ & Superstructure & Deck \\
Precast-Single-tee & $4^{\prime} * 3^{\prime}(1.2 \mathrm{~m} * 0.9 \mathrm{~m})$ & Superstructure & Deck \\
Concrete & $9^{\prime \prime} * 12^{\prime \prime}\left(0.2 \mathrm{~m}^{*}\right.$ & Deck & Curb \\
Rectangular Beam & $0.3 \mathrm{~m})$ & & \\
Foundation Slab & $9^{\prime \prime}(0.2 \mathrm{~m})$ & Deck & Deck \\
\hline
\end{tabular}


81 | ASEAN Journal of Science and Engineering, Volume 2 Issue 1, March 2022 Hal 77-90

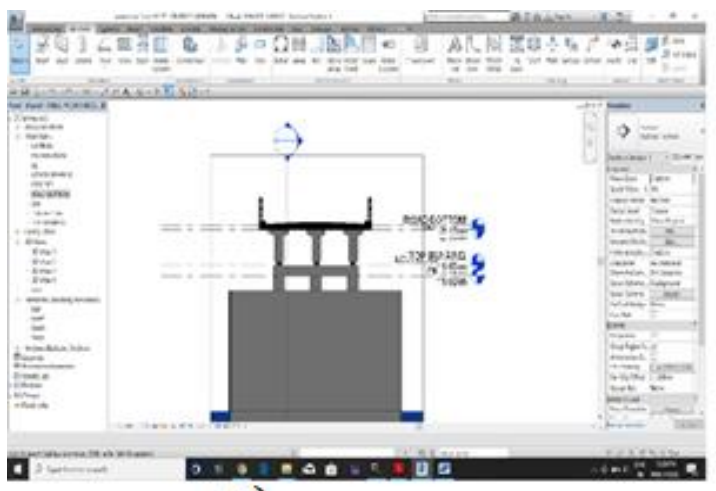

a)

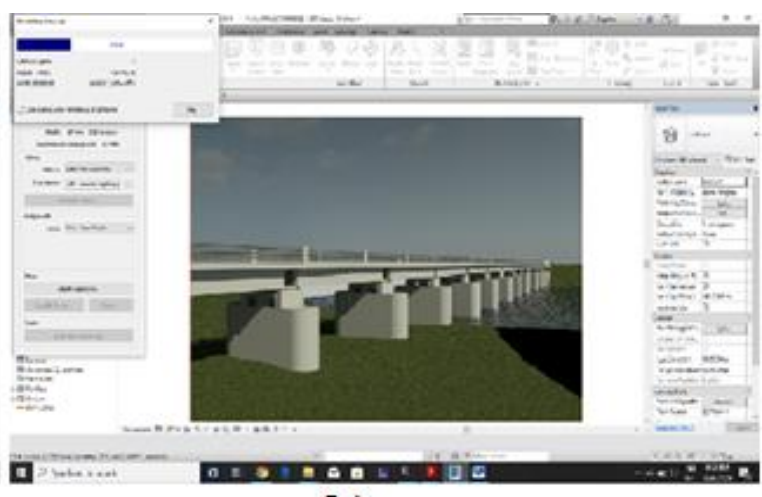

b)

Figure 3. a) Sectional view of structure; b) 3D Model.

\subsection{Analysis of The 3D Bridge Model}

To check structural behavior of bridge under lateral load (check displacement), to find the displacement due to flood water pressure along with debris, and to verify after analysis whether the displacement is within the permissible limit or not and if it is not then there is need to suggest possible efficient rehabilitation solution. After analyzing the Bridge structure in Staad.Pro, it is suggested that by providing angle section and post-tensioning cable the structure can be rehabilitated for regular use. The structural analysis of the model was carried out in Staad.Pro software and the result shows the structural behavior in the form of deflection, bending moment, and shear force value which is further used for developing the solution.

\subsubsection{Geometry for The Model}

Figure 4 shows the geometry of the bridge structure having fixed support for each span and with simply supported beam condition for specific spacing of each $12 \mathrm{~m}$ span. Fixed support has restraints against all directions of movement. The Members were assigned properties as main beam and secondary Tee beam based on the function. Properties of the Material are assigned as per the member properties (Ref.IS 456: 2000- Plain and Reinforced Concrete and IS 800: 2007-General Construction in Steel) to the whole structure.

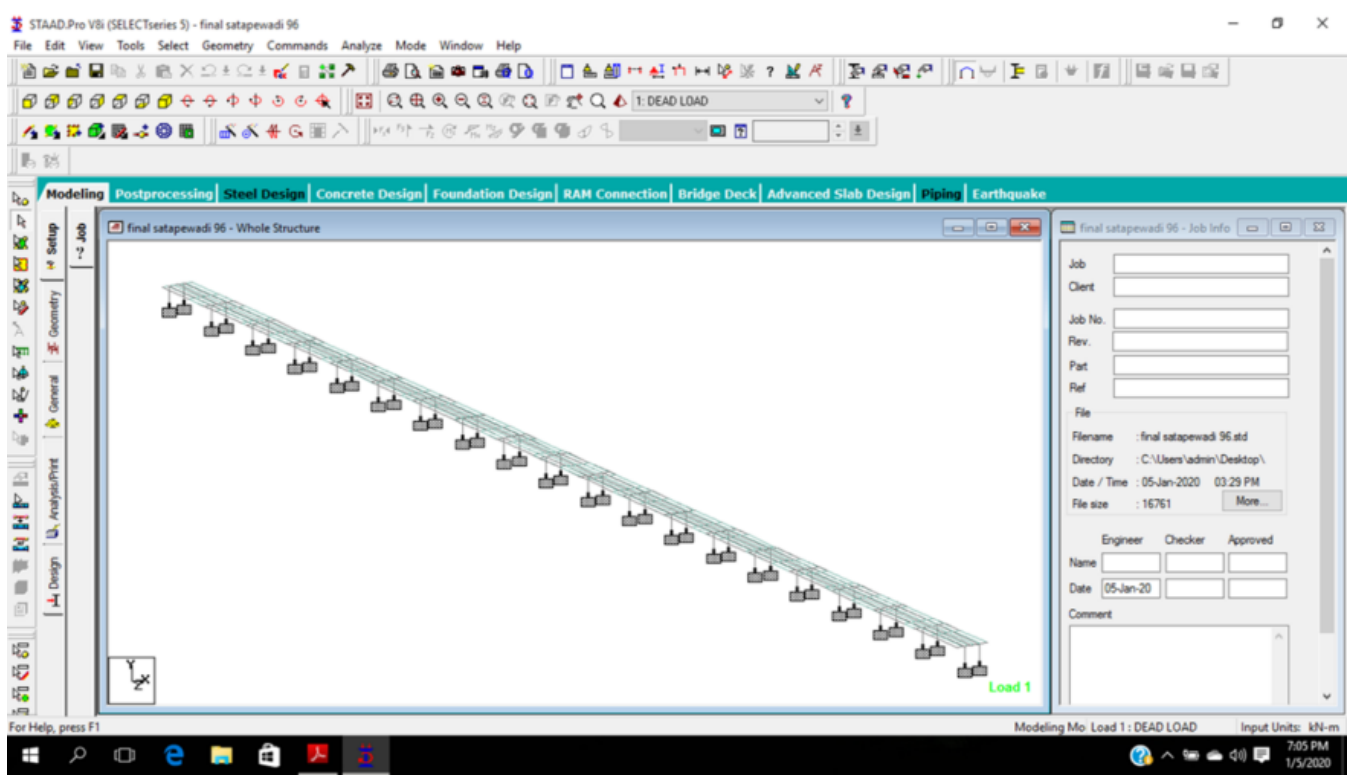

Figure 4. Geometry. 


\subsubsection{All Beams Are Safe}

As per IS 456: 2000 (Plain and Reinforced Concrete) when the loads are assigned as selfweight and load transferred from the members, it is observed after calculations in the software that for design load condition and load combinations bending moment (BM), shear force (SF), and deflection in beams are within permissible limits. Table $\mathbf{3}$ means that all beams are safe against defined load as per specifications (see Figure 5).

\subsubsection{Respected Live Load (LL) Value and Bending Moment (BM)}

As per IRC: 6- 2000 (Loads and stress) Clause No. 201.1 IRC class AA loading is to be adopted within certain municipal limits, in a certain existing or contemplated industrial area, in other specified areas, and along certain specified highways. As per IRC class, AA loading condition the intensity of loading due to vehicular load is $15.69 \mathrm{kN} / \mathrm{m}^{2}$, and live load bending moment because the living loads of $155.61 \mathrm{kN} / \mathrm{m}^{2}$ are within the permissible limit, there is no deflection which is safe against buckling as shown in Figure 6.

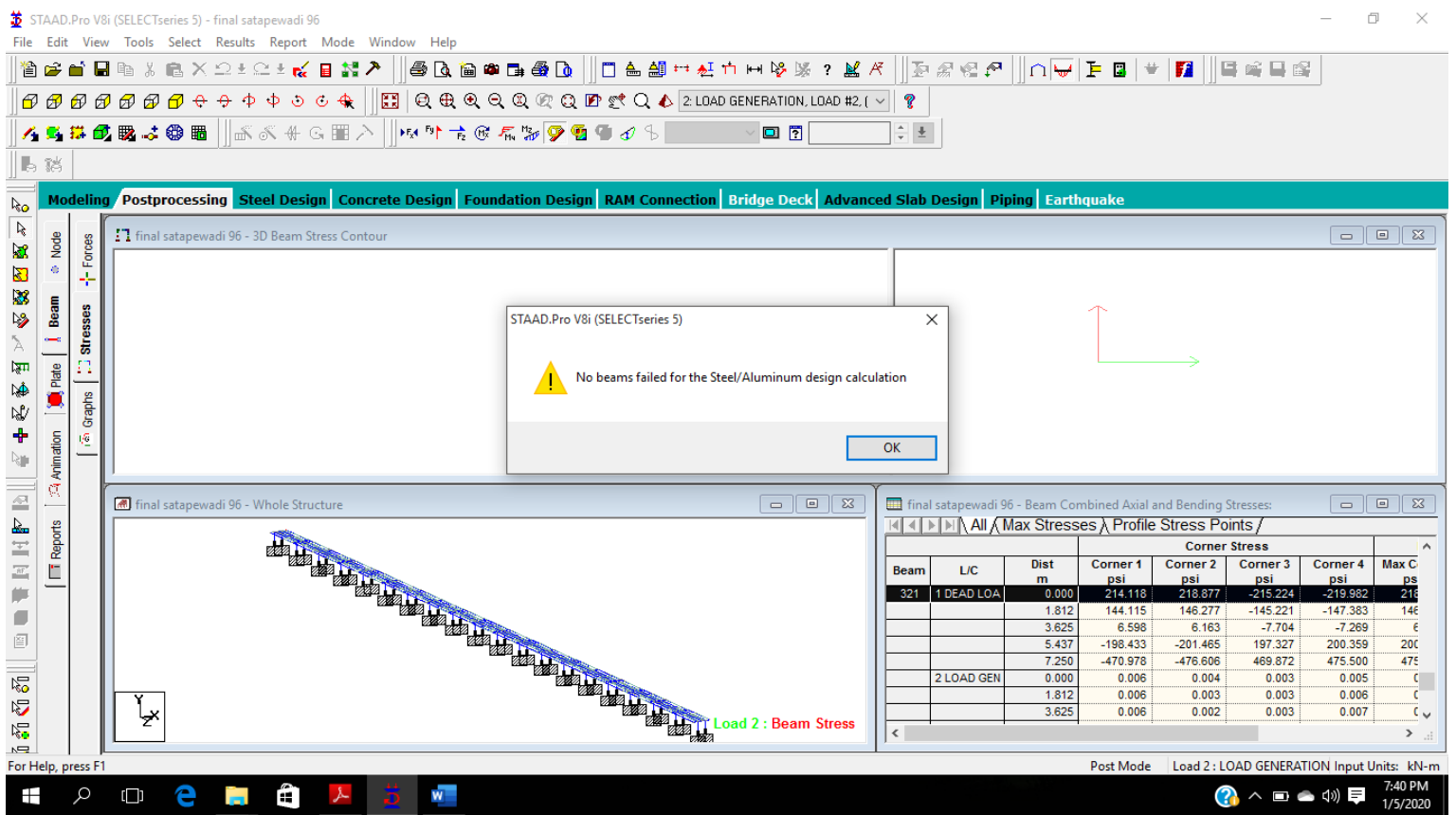

Figure 5. All beams are safe.

Table 3. Staad.Pro results.

\begin{tabular}{ccc}
\hline & Maximum & Permissible limits \\
\hline Bending Moment & $1177.47 \mathrm{KNm}$ & $1235 \mathrm{KNm}$ \\
Shear Force & $708.67 \mathrm{KN}$ & $802 \mathrm{KN}$ \\
Moving Load & $15.69 \mathrm{kN} / \mathrm{m}^{2}$ & $20.80 \mathrm{kN} / \mathrm{m}^{2}$ \\
\hline
\end{tabular}




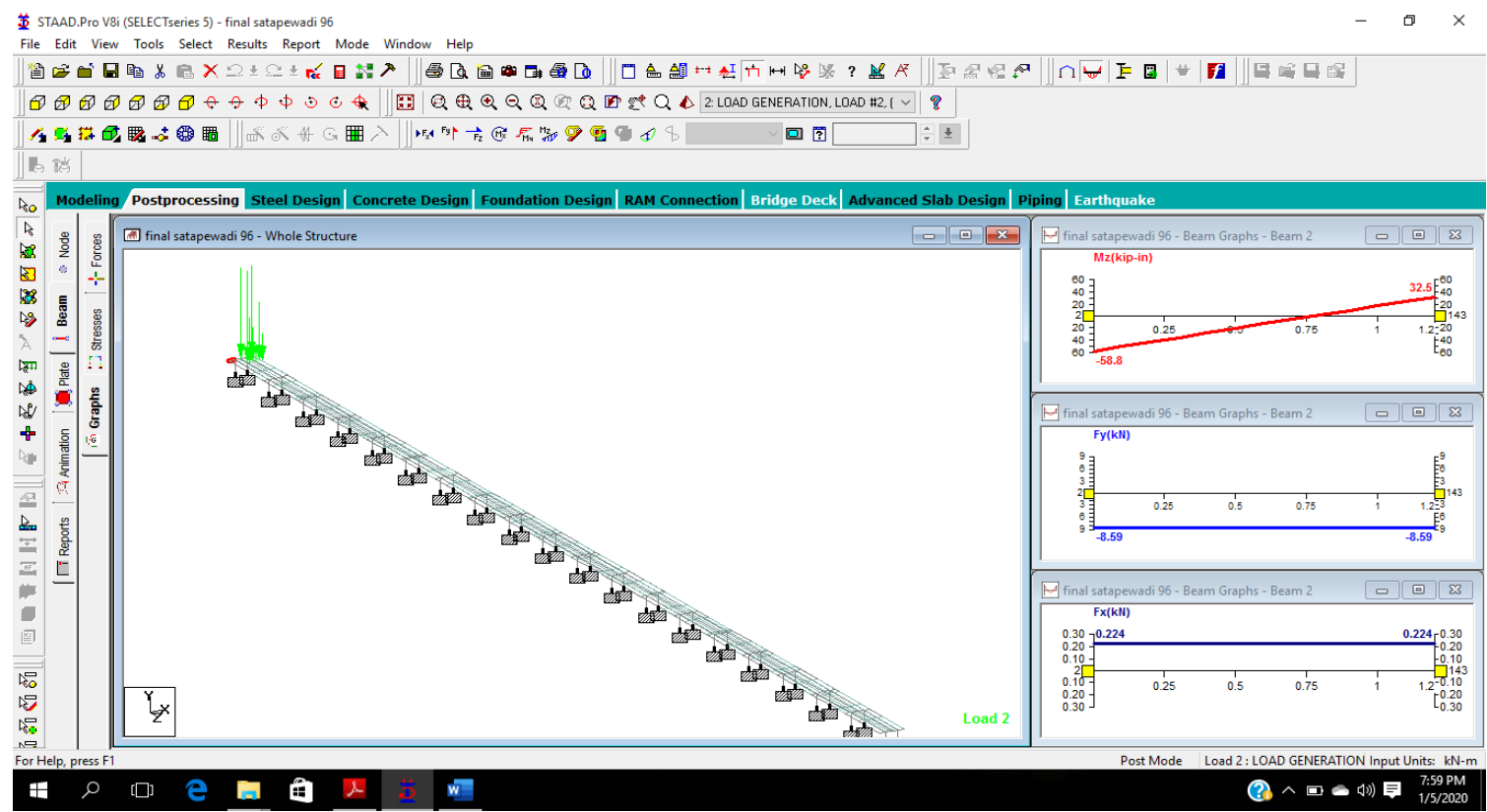

Figure 6. Respected moving load value and bending moment.

\subsubsection{Analysis of Horizontal Forces Due to Water Currents}

As per IRC:6- 2000 (Loads and stress) Clause No. 210 intensity of horizontal forces due to flood-water pressure is $10.18 \mathrm{kN} / \mathrm{m}^{2}$. Line model of bridge substructure as showin in Figure 7 is prepared and analysis is done with and without water pressure.

After analysis, it can be observed that displacement in Table 4 is increased by $20 \%$. As per the Indian Road Congress (IRC), it is unsafe for use therefore, a rehabilitation solution is provided after analysis in section 3.4 to overcome the displacement of deck slab caused due to high water pressure.

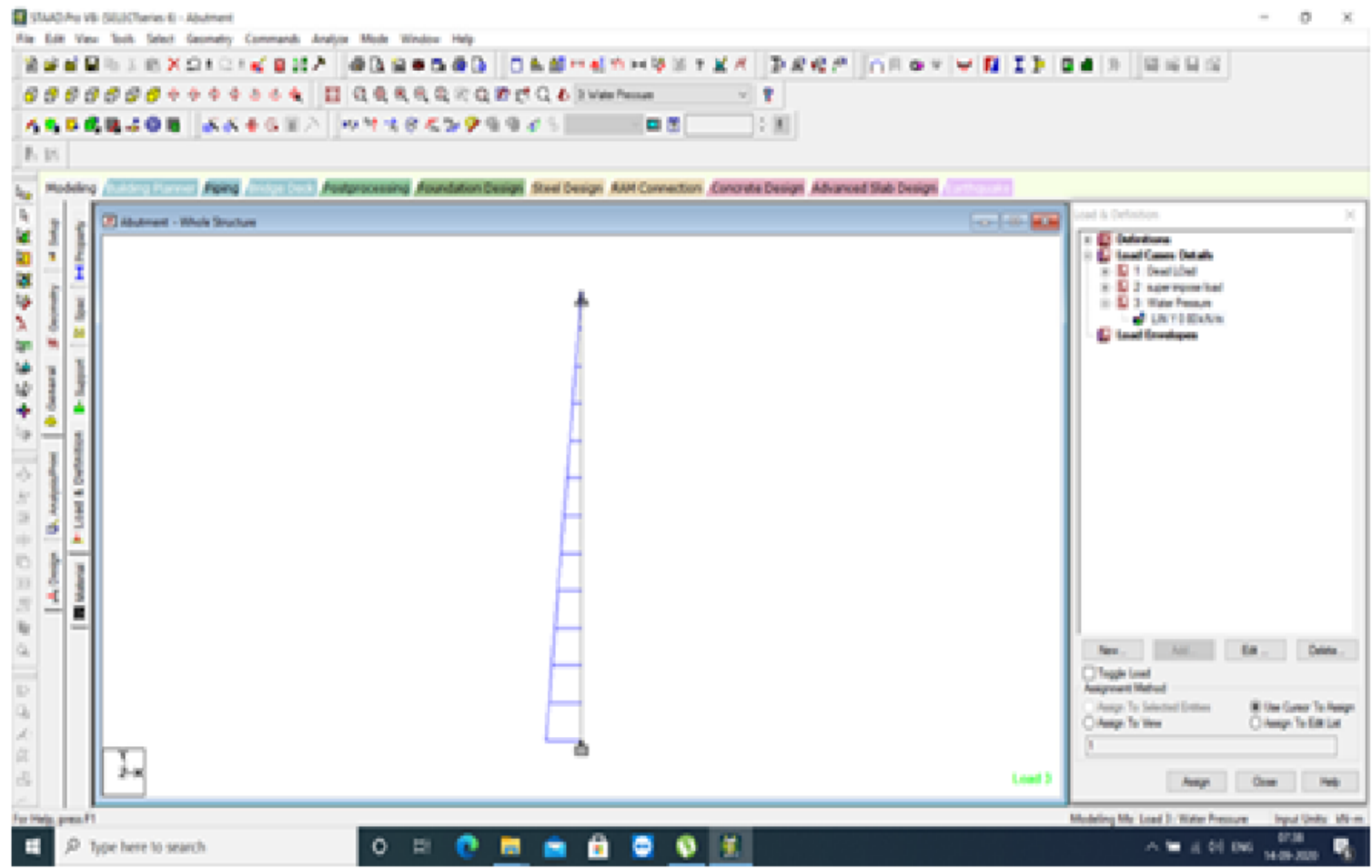

Figure 7. Horizontal forces due to water currents. 
Table 4. Displacement of the superstructure.

\begin{tabular}{ccc}
\hline Component & $\begin{array}{c}\text { Moment Without Water } \\
\text { Pressure }\end{array}$ & $\begin{array}{c}\text { Moment With Water } \\
\text { Pressure }\end{array}$ \\
\hline Superstructure & $12 \mathrm{~mm}$ Y-direction & $18 \mathrm{~mm} \mathrm{X}$ - direction \\
& $15 \mathrm{~mm} \mathrm{Y}$ - direction \\
\hline
\end{tabular}

\subsection{Rehabilitation Solution}

A structure can substantially get damaged due to a flood. In such a situation rehabilitation of bridges becomes necessary on account of changes caused due to abnormal floods condition, as per IRC SP: 40 (Guidelines for techniques for strengthening and rehabilitation of bridges).

Providing strengthening option to bridge in case of normal applications it is done in prestressed concrete or post-tensioned Systems which should comply with the requirements of the IRC code for Acceptance and Applications of Post-Tensioned Systems. As per specifications of IRC SP: 40, Clause no 6.2.4.6- Strengthening with other methods is as follows: 1. Providing post-tensioning angle section in the longitudinal direction for bridge deck slab and $\mathrm{T}$ beam.

2. Concrete slabs or beams or columns can be strengthened by providing reinforced concrete jackets or overlays. Normally, the thickness of the new concrete layer should be less than about $1 / 3$ rd of the thickness of the existing concrete.

3. Providing post-tensioning cable for deck slab.

\subsubsection{Detailed solution}

To rehabilitate or strengthen a structure, replacement of structural systems or addition of the new system to the existing structure is sometimes adopted.

\subsubsection{Providing post-tensioning angle section in the longitudinal direction for bridge deck slab and $T$ beam}

The solution is developed as a post-tensioning angle section in the longitudinal direction for the bridge deck slab and the T beam is shown in Figure 8. Each span provided three-angle sections.

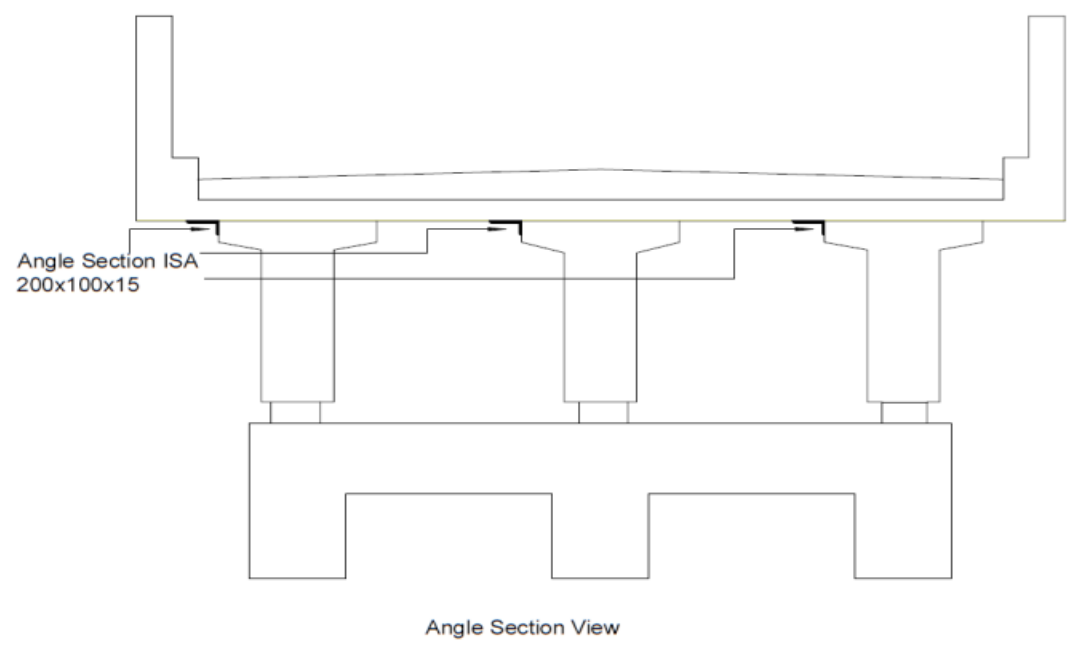

Figure 8. Angle section arrangement. 
85| ASEAN Journal of Science and Engineering, Volume 2 Issue 1, March 2022 Hal 77-90

There are several factors:

(i) Section Properties. As per IS 800: 2007 (General Construction in Steel) post-tensioning Angle section (see Table 5) provided as follows their properties.

(ii) Properties of the bolt connection. The connectivity of the angle section with bolt is shown in Table 6.

(iii) General Cost Information. General cost information for post-tensioning deck slab and T beam providing angle section. Provided 3 angle sections for $3 \mathrm{~T}$ beams in a single span. Total 57 angle sections are provided (see Table 7) and provide 3 bolts for each angle connection (see Table 8). The total number of bolts is 171 .

The total material cost for post-tensioning of the angle section is- Rs. 51,565 (\$711.56).

Table 5. Properties of angle section.

\begin{tabular}{lc}
\hline \multicolumn{1}{c}{ Parameter Considered } & Value \\
\hline 1. Water Pressure & $3.030 \frac{\mathrm{KN}}{\mathrm{m}^{2}}$ \\
a)Normal water pressure & $10.18 \frac{\mathrm{KN}}{\mathrm{m}^{2}}$ \\
b) Water pressure at flood time & $26.87 \mathrm{KN}$ \\
$\begin{array}{l}\text { Force on deck } \\
\text { 2. Stress- } \\
\text { Permissible bending stress- } \\
\text { Section modulus required }\end{array}$ & $330 \frac{\mathrm{N}}{\mathrm{mm}^{2}}$ \\
$\begin{array}{l}\text { 3. Section Selection } \\
\text { Providing angle section- }\end{array}$ & $122.18 \times 103 \mathrm{~mm}^{3}$ \\
\hline
\end{tabular}

Table 6. Properties of bolt.
1. Shear strength of the bolt
$20.89 \mathrm{KN}$
2. No. of bolts providing
3

Table 7. Angle section cost information.

\begin{tabular}{|c|c|c|}
\hline 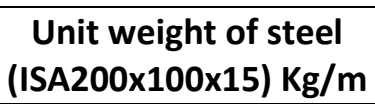 & $\begin{array}{l}\text { The total length of } \\
\text { angle section } \mathrm{Kg}\end{array}$ & Cost Rs. $(45 / \mathrm{kg})$ \\
\hline 33.55 & 27.36 & 41,305 \\
\hline
\end{tabular}

Table 8. Bolt cost information.

\begin{tabular}{ccc}
\hline Bolt size (Mm) & Total number of bolts & Cost Rs. (60/bolt) \\
\hline 12 & 171 & 10,260 \\
\hline
\end{tabular}

\subsubsection{Providing post-tensioning cable for deck slab}


A cable is provided for the deck slab to withstand high water pressure refer to Figure 9. By resolving all the forces in the cable as per floodwater pressure of $10.18 \mathrm{kN} / \mathrm{m}^{2}$ coming on deck slab, and by considering maximum tension in the cable the anchor block is designed for the structure as detailed in Table 9.

Equation of equilibrium is used for resolving the force system of the cable as given below. $\sum F_{x}=0$

$\mathrm{F}_{1} \operatorname{Cos} \alpha 1-\mathrm{F}_{2} \operatorname{Cos} \alpha 2=0$

$\therefore \mathrm{F}_{1}=\mathrm{F}_{2} \frac{\cos \alpha 2}{\operatorname{Cos} \alpha 1}$

$\sum \mathrm{F}_{\mathrm{y}}=0$

$\mathrm{F}=\mathrm{F}_{1} \operatorname{Sin} \alpha 1+\mathrm{F}_{2} \operatorname{Sin} \alpha 2$

$\therefore \mathrm{F}=\mathrm{F}_{2} \frac{\operatorname{Cos} \alpha 2}{\operatorname{Cos} \alpha 1} \operatorname{Sin} \alpha 1+\mathrm{F}_{2} \operatorname{Sin} \alpha 2$

...........(From equation i)

$\therefore \mathrm{F}=\left\{\left(\frac{\operatorname{Cos} \alpha 2}{\operatorname{Cos} \alpha 1} \operatorname{Sin} \alpha 1\right)+\operatorname{Sin} \alpha 2\right\} F_{2} .$. from (i)

$\therefore \mathrm{F}_{2}=\frac{F}{\left\{\left(\frac{\operatorname{Cos} \alpha 2}{\operatorname{Cos} \alpha 1} \operatorname{Sin} \alpha 1\right)+\operatorname{Sin} \alpha 2\right\}}$

Design of Anchor block is done considering submerged soil condition having a unit weight of soil above the anchor block in Table 10.

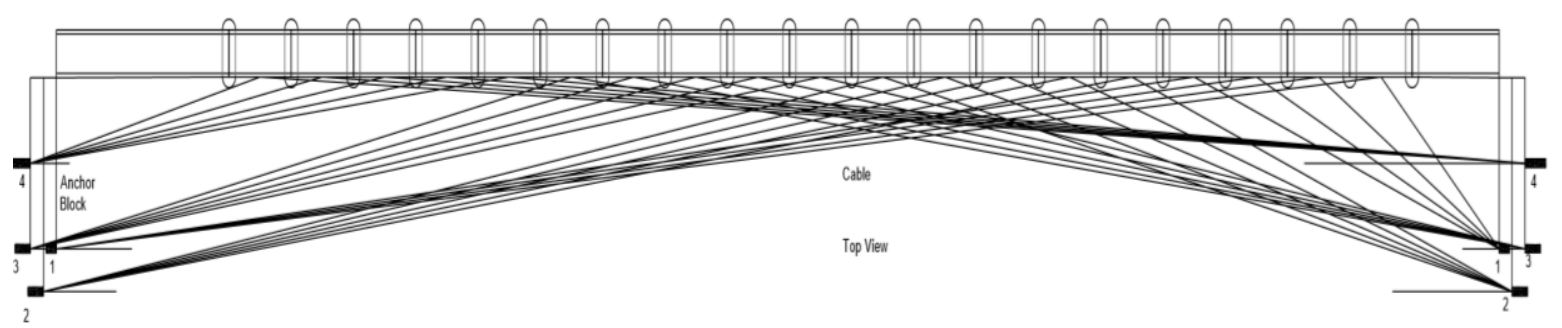

Figure 9. Cable with anchor block.

Table 9. Maximum tension in the cable.

\begin{tabular}{|c|c|c|}
\hline Span No. & $\mathrm{F} 1=(\cos \alpha 2 / \cos \alpha 1) \mathrm{F} 2$ & $\mathrm{~F} 2=\mathrm{F} /((\cos \alpha 2 / \cos \alpha 1) * \sin \alpha 1+\sin \alpha 2)$ \\
\hline 5 & 60.86738181 & 57.98635467 \\
\hline 6 & 68.28918647 & 66.13893379 \\
\hline 7 & 71.06547177 & 69.63363663 \\
\hline 8 & 74.28581257 & 73.09442368 \\
\hline
\end{tabular}

Table 10. Details of anchor block.

\begin{tabular}{ccccccc}
\hline $\begin{array}{c}\text { Block } \\
\text { No. }\end{array}$ & $\begin{array}{c}\text { Weight of soil } \\
\text { per } \boldsymbol{m}^{\mathbf{2}}\left(\frac{\boldsymbol{k} \boldsymbol{N}}{\boldsymbol{m}^{\mathbf{2}}}\right)\end{array}$ & $\begin{array}{c}\text { Weight of } \\
\text { block }(\boldsymbol{K N})\end{array}$ & $\begin{array}{c}\text { Dimension } \\
\text { of Block } \\
(\boldsymbol{m})\end{array}$ & $\begin{array}{c}\text { Area of } \\
\text { cable } \\
\left(\boldsymbol{m m}^{\mathbf{2}}\right)\end{array}$ & $\begin{array}{c}\text { Cable } \\
\text { Diameter } \\
(\boldsymbol{m} \boldsymbol{m})\end{array}$ & $\begin{array}{c}\text { Development } \\
\text { length }(\boldsymbol{m m})\end{array}$ \\
\hline 1 & 45 & 90 & $2 \times 1$ & 151.35 & 14 & 801.31 \\
2 & 27 & 81 & $3 \times 1$ & 170.75 & 15 & 858.55 \\
3 & 36 & 108 & $3 \times 1$ & 222.02 & 17 & 973.02 \\
4 & 54 & 216 & $4 \times 1$ & 394.50 & 23 & 1316.44 \\
\hline
\end{tabular}

\subsubsection{General cost information}


The total weight of the cable provided with the anchor block is 10.28 tons. It has 8 concrete anchor blocks with base connection cable to deck along with 38 flat anchor plates with the tensile strength of $544 \mathrm{Mpa}$. Information regarding the cost incurred for cable with anchor block is given in Table 11.

The total material cost for a post-tensioning cable with an anchor block is Rs. 5,22,382 (\$ 7208.52).

\subsection{D Model}

After the model was analyzed for rehabilitation and found safe against all load conditions, then 4D (time component-construction planning and scheduling) components are applied. The 4D-BIM includes the time factor that was applied in the construction planning and scheduling for bridge rehabilitation. Rehabilitation of bridge may complete within 76 days (2.5 Months) without missing out on any activity in that main activity given in (Table 12). Navisworks was the software used to create the 4D model. The construction planning and scheduling can be created directly in Navisworks. A Gantt chart (Figure 10), about the rehabilitation of the deck slab segment, Navisworks was established directly within it. Each task was linked to the corresponding construction component (Pier, Bearing, Tee Beam, and Deck Slab).

Table 11. General cost information of cable with an anchor block.

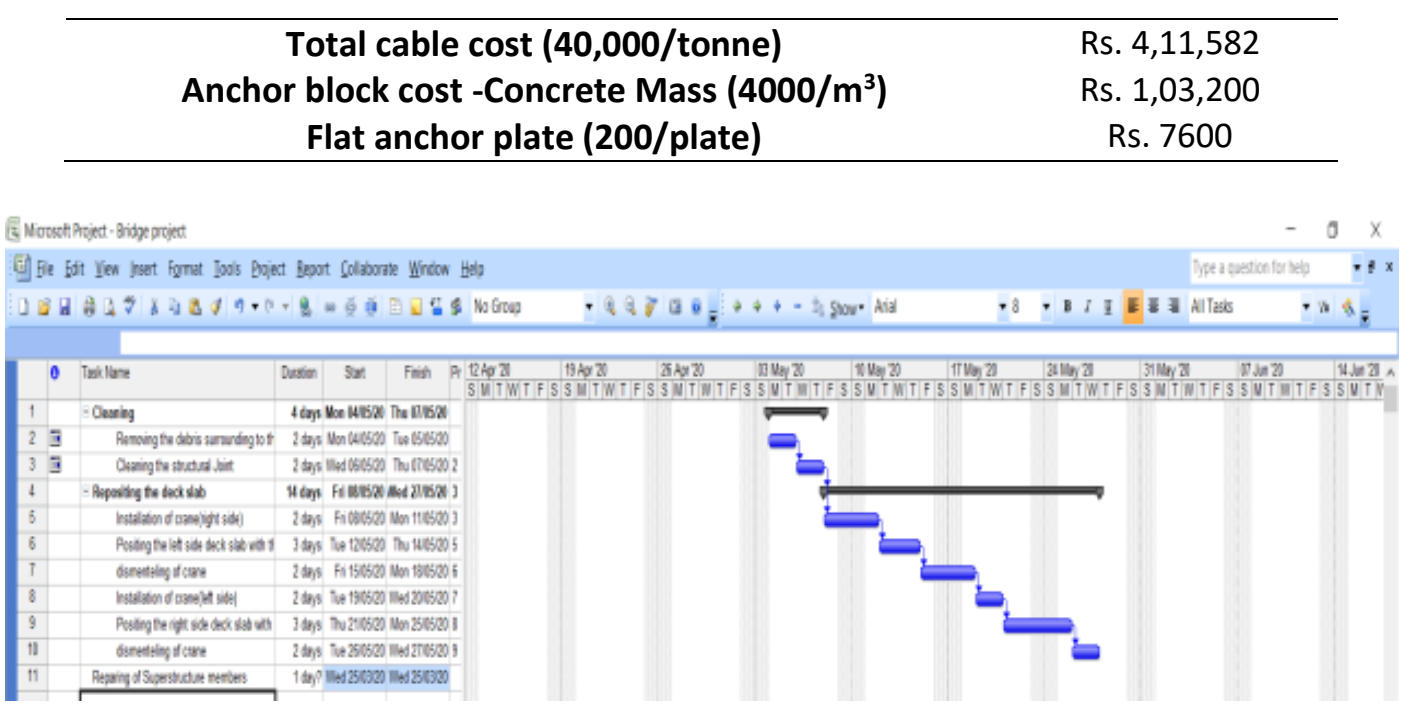

Figure 10. Planning and scheduling using MSP Software.

Table 12. Main activity.

\begin{tabular}{cc}
\hline Activity & Duration (76 Days) \\
\hline Existing deck slab & 10 Days \\
Removal of debris & 5 Days \\
Providing new bearing pad & 10 Days \\
Repositioning of the deck slab & 15 Days \\
Application of angle section & 20 Days \\
Repairing of Expansion Joint & 5 Days \\
Repairing of railing & 8 Days \\
Applying wearing coat & 2 Days \\
Rehabilitated bridge deck slab & 1 Day \\
\hline
\end{tabular}


The different construction/repair phases are: for the existing deck slab; replacement of bearing; removal of bearing; replacing the deck slab; application of angle section to deck slab; repairing of expansion joint; and repairing of the railing.

Each set was created by selecting the components of the geometric model that correspond to that phase. Construction tasks were added, including the planned beginning and end dates. To create the construction sequence, the TimeLine command was used in the Home tab and Tools panel to Refer to Figure 11.

The elements represented in red were the object of construction during the task, and the elements in green correspond to a removal or demolition process as part of the task. The simulation of the different tasks planned for the deck slab rehabilitation was obtained through the simulate tab of the Timeline command. Figure 12 represents the construction phase (a) existing (displaced) deck slab; (b) reposition of deck slab and removal debris; (c) providing new bearing pads; (d) applying the wearing coat.

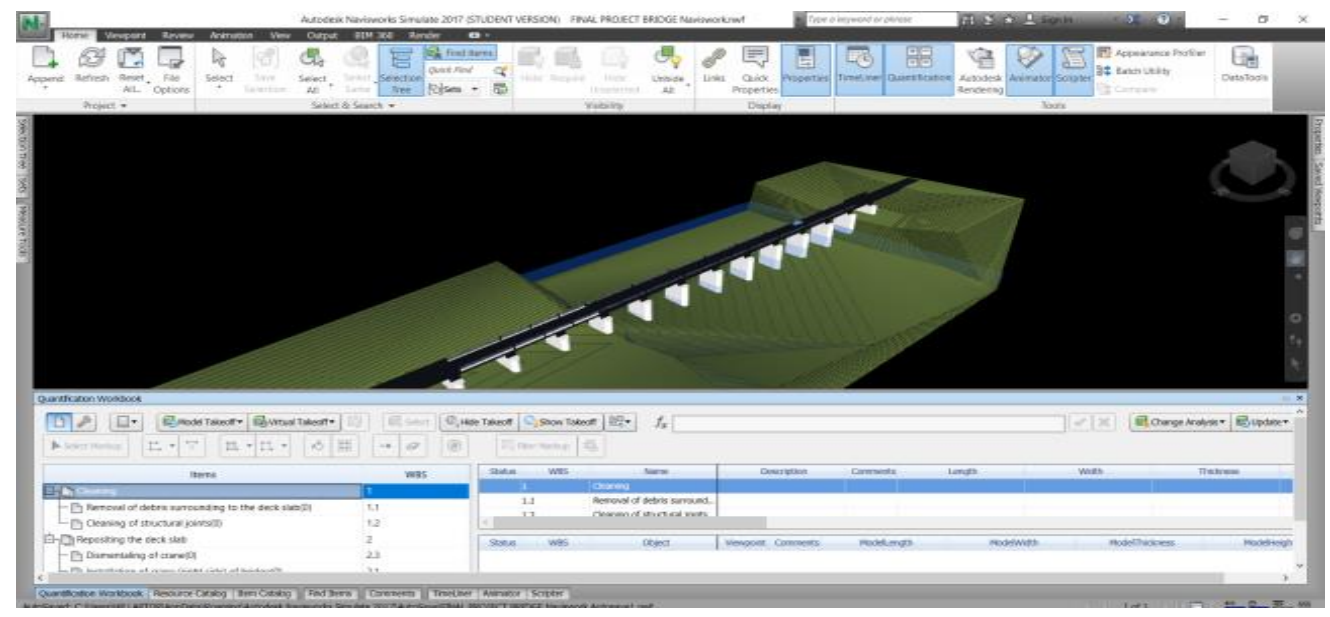

Figure 11. The results of navisworks generation of 4D BIM model.
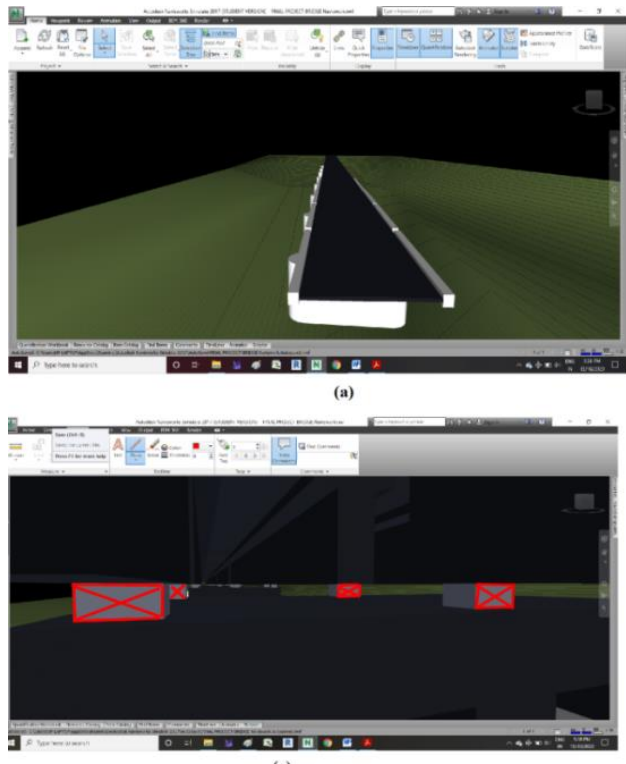

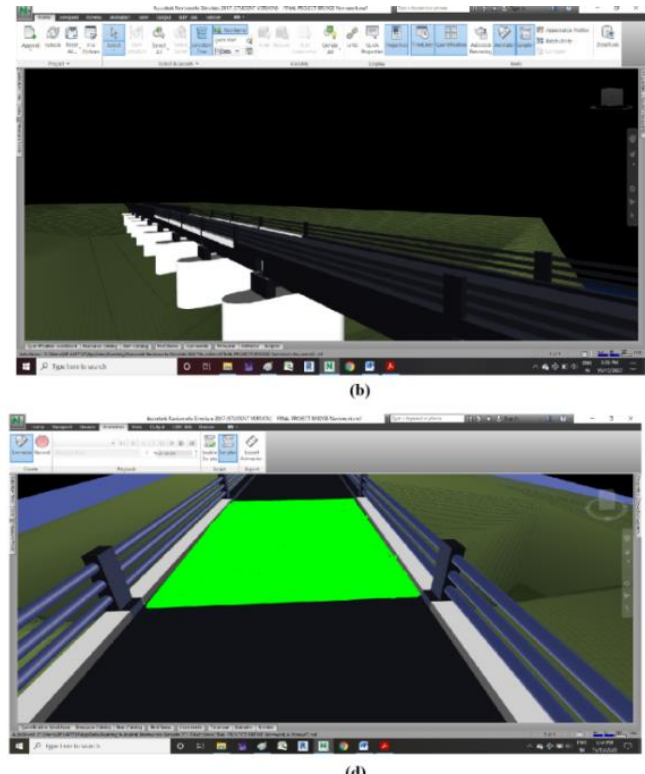

Figure 12. The 4D Model of construction phases.

\subsection{General Guideline for Repairs to Expansion Joints, Bearing, Railing}

As per IRC SP: 40 (Guidelines for techniques for strengthening and rehabilitation of bridges) clause no 7 general guidelines provided as follows: 
89 | ASEAN Journal of Science and Engineering, Volume 2 Issue 1, March 2022 Hal 77-90

(i) Expansion Joint- The replacement joint should be watertight across the full width of the deck. Debris may prevent joint movement if the filler fails and may damage the joint sides or joint material, it may spall the sides of jointed slabs or cause over-stress in other bridge elements.

(ii) Bearing- Repair or replacement of bearings requires traffic restrictions or even a temporary suspension of traffic.

(iii) Railing- A decision to repair or replace these items should be taken keeping in view the economics and the importance of the appearance of the bridge.

\section{RESULTS AND DISCUSSION}

In BIM, it is possible to use tools that allow for the extraction of a range of information from the models created. One of the most important components of a BIM is the drawing outputs, and it is a fundamental requirement that the designer can easily update them when changes and adjustments are made to the project. It was likewise possible to extract information on deck slab, bearing, railing elements. The results after the design as per IRC: SP 40 (Guidelines for techniques for strengthening and rehabilitation of bridges) considering floodwater pressure of $10.18 \mathrm{kN} / \mathrm{m} 2$ which is exerting $26.87 \mathrm{kN}$ pressure on deck slab is the required angle section of the dimensions ISA $200 * 100 * 15(\mathrm{~mm})$.

Analysis of horizontal water pressure shows that displacement of deck slab with and without water pressure is increased by $20 \%$ and to overcome that displacement we need to provide an angle section to strengthen the deck slab.

In BIM, it is possible to use tools that allow for the extraction of a range of information from the models which is created by using BIM. One of the most important components of a project is the drawing outputs, and it is a fundamental requirement that the designer can easily update them when changes and adjustments are made to the project (Bryde, 2013). It was likewise possible to extract information on deck slab, bearing, railing elements.

The behavior of the bridge was checked by providing a rehabilitation solution using the Stadd Pro software. By providing an angle section and post-tensioning cable with an anchor block reduces displacement within permissible limits. Maximum displacement values of deck slab after providing angle section and post-tensioning cable are $8.55 \mathrm{~mm}$ and $5.53 \mathrm{~mm}$ respectively. Based on this analysis it is seen that under the influence of post-tensioning cable with an anchor block is structurally safe with fewer displacement values.

Nevisworks allows access of 3D models to 4D navigates around them in real-time, and reviews the model using a set of tools. By using the Nevisworks work process shows the most economical rehabilitation solution of the post-tensioning angle section to the deck slab, with the duration of 76 days as per Nevisworks analysis.

\section{CONCLUSION}

The application of the BIM methodology consisted of three phases:

(i) Creation of the project model (3D) which shows an actual visualization of bridge deck slab;

(ii) The design provided for rehabilitation is within the permissible limit as per IRC class AA loading condition the intensity of loading due to vehicular load is $15.69 \mathrm{kN} / \mathrm{m}^{2}$ and the live load bending moment is $155.61 \mathrm{kN} / \mathrm{m}^{2}$ against $20.80 \mathrm{kN} / \mathrm{m}^{2}$ and $170.62 \mathrm{kN} / \mathrm{m}^{2}$ permissible limits respectively.

(iii) Hydraulic analysis of bridge structure shows that displacement increased by $20 \%$. It is not safe for the total functionality of the bridge, hence an angle section is provided to the deck slab to limit displacement. 
(iv) Analysis of the two solutions provided shows that providing an angle section is $90.12 \%$ more economical than the use of post-tensioning cables with an anchor block.

(v) Use of Navisworks gives work process in 4D outputs, for economical rehabilitation solution the duration required is 76 days as per Navisworks analysis.

\section{ACKNOWLEDGMENTS}

We acknowledged Prof. D. S. Patil (Head of Program) and Dr. P. D. Kumbhar (Head of Department) for their valuable suggestions, critical examination of work during the progress. We also thank Mr. Rohit Desai, Mr. Sunil Ben, and Mr. Mangesh Karanjkar for giving me insight into BIM.

\section{AUTHORS' NOTE}

The author(s) declare(s) that there is no conflict of interest regarding the publication of this article. The authors confirmed that the data and the paper are free of plagiarism.

\section{REFERENCES}

Bryde, D., Broquetas, M., and Volm, J. M. (2013). The project benefits of building information modelling (BIM). International Journal of Project Management, 31(7), 971-980.

Clevenger, C. M., Ozbek, M. E., Mahmoud, H., and Fanning, B. (2014). Impacts and benefits of implementing building information modeling on bridge infrastructure projects. The National Academies Science, Engineering, Medicine, MPC 14-272, 1-28.

Marzouk, M. M., and Hisham, M. (2012). Bridge information modeling in sustainable bridge management. ICSDC 2011: Integrating Sustainability Practices in the Construction Industry, ICSDC 2011, 457-466.

McGuire, B., Atadero, R., Clevenger, C., and Ozbek, M. (2016). Bridge information modeling for inspection and evaluation. Journal of Bridge Engineering, 21(4), 04015076.

\section{Codes:}

IS 456: 2000- Plain and Reinforced Concrete.

IS 800: 2007- General Construction in Steel.

IRC SP: 40- Guidelines for techniques for strengthening and rehabilitation of bridges.

IRC: 6- 2000 (Loads and stress). 